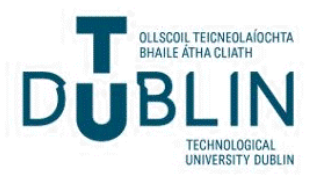

Technological University Dublin ARROW@TU Dublin

2017-11-13

\section{Ka-band Vivaldi Antenna with Novel Core Element for High-Gain}

\author{
Manh-Ha Hoang \\ Technological University Dublin, manhha.hoang@mydit.ie \\ Kansheng Yang \\ Technological University Dublin \\ Matthias John \\ Trinity College Dublin, matthias.john@tudublin.ie
}

See next page for additional authors

Follow this and additional works at: https://arrow.tudublin.ie/ahfrccon

Part of the Systems and Communications Commons

\section{Recommended Citation}

Hoang, M. Ha, Yang et al. (2017) Ka-band Vivaldi Antenna with Novel Core Element for High-Gain, LAPC Loughborough Antennas \& Propagation Conference, Loughborough, UK, 2017.

This Conference Paper is brought to you for free and open access by the Antenna \& High Frequency Research Centre at ARROW@TU Dublin. It has been accepted for inclusion in Conference Papers by an authorized administrator of ARROW@TU Dublin. For more information, please contact arrow.admin@tudublin.ie, aisling.coyne@tudublin.ie, gerard.connolly@tudublin.ie.

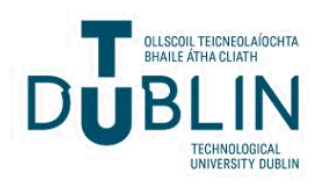




\section{Authors}

Manh-Ha Hoang, Kansheng Yang, Matthias John, Patrick McEvoy, and Max Ammann 


\title{
Ka-band Vivaldi Antenna with Novel Core Element for High-Gain
}

\author{
Manh-Ha Hoang, Kansheng Yang, Matthias John, Patrick McEvoy, Max Ammann \\ Antenna and High-Frequency Research Centre - Dublin Institute of Technology \\ manhha.hoang@mydit.ie
}

Keywords: Vivaldi antenna, double slot, parasitic element, Ka and mm-wave bands, Vivaldi feeds.

\begin{abstract}
A high gain Vivaldi antenna employing an integrated core element is proposed. The maximum antenna gain is $16.9 \mathrm{dBi}$ and it performs better than $14 \mathrm{dBi}$ over the complete $\mathrm{Ka}(24-40 \mathrm{GHz})$ band. The design methodology, excitation arrangement and field distribution features are described.
\end{abstract}

\section{Introduction}

Using a tapered slot, Vivaldi antennas provide a wide impedance bandwidth and moderate gain. They are fabricated using low-cost planar fabricating technology. Hence, they are used in many applications which demand wide or ultra-wide bandwidth and directional radiation properties, such as UWB imaging systems and emerging $5 \mathrm{G}$ systems.

However, the gain of conventional Vivaldi antennas is limited, even when the length of the antenna is increased. There has been some work reported which tackled the problem of limited Vivaldi antenna gain. A dielectric-load was used for the antenna in Ka-band [1], while [2] added anisotropic zero-index metamaterials (ZIM) in the aperture of a UWB Vivaldi antenna to improve gain. A double-slot and double-antipodal structures were employed in [3] and [4]. Additionally, a parasitic elliptical core element was also shown to improve gain and beamwidth for the Vivaldi antenna [5, 6].

In this paper, the study of Vivaldi antenna excitation methods with a core element shows that this antenna can excite a wavemode on two sides of the core element which have the same characteristic as the wave-mode on the double slot structure in [3]. The role played by the length of the core element in improving gain is described.

\section{Antenna Design}

The basis of the structure is shown in Fig.1. This structure is a combination of a double slot Vivaldi antenna and a core element. Energy transfers to/from this core element at the feed points as well as along the Vivaldi tapered slot curve.

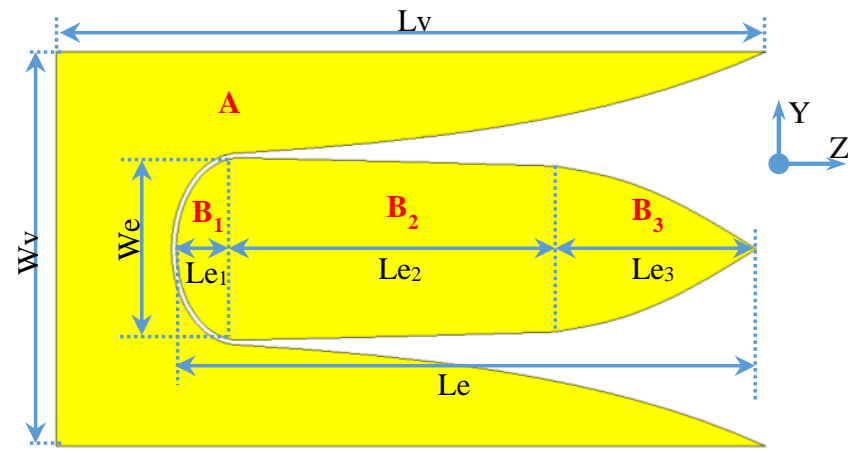

Fig.1: Vivaldi antenna structure with a core element

This structure has two main parts including the ground plane (A) with two symmetrical exponential curves. Initially, a parasitic core is employed, which is divided into three subparts $\left(\mathrm{B}_{1}, \mathrm{~B}_{2}\right.$ and $\left.\mathrm{B}_{3}\right) . \mathrm{B}_{1}$ is a half ellipse, which combines with part $\mathrm{A}$ to create a slot line. $\mathrm{B}_{2}$ has a slight exponential taper and connects $B_{1}$ to $B_{3}$. These exponential curves create a double Vivaldi slot. $B_{3}$ is an extension of $B_{2}$ with two spline curves which meet at the centre.

The dimensions are shown in Table 1 . This antenna is designed on RT5880 $\left(\mathrm{e}_{\mathrm{r}}=2.2\right.$ and $\left.\tan \delta=0.0009\right)$ material with $0.25 \mathrm{~mm}$ thickness.

\begin{tabular}{|c|c|}
\hline Dimensions & Value $(\mathbf{m m})$ \\
\hline$W v$ & 20.56 \\
\hline$L v$ & 37 \\
\hline$L e$ & 30.25 \\
\hline$L e_{1}$ & 3.34 \\
\hline$L e_{2}$ & 16.41 \\
\hline$L e_{3}$ & 10.5 \\
\hline$W e$ & 9.5 \\
\hline
\end{tabular}

Table 1: Dimensions of the structure

\subsection{Excitation methods for the structure}

Due to the planar technology, the slot excitation by stubs is appropriate. Fig. 2 describes excitation method 1 for the slot. The slot is excited by two stubs from outside the core, which are placed symmetrically at the centre and connected to a Tdivider. To ensure the field vectors radiating from the two Vivaldi slots have the same direction at the radiating aperture, the phase at the two stubs are $180^{\circ}$ out of phase so that the 
electrical length difference of the two microstrip lines feeding the stubs $\left(d_{1}\right)$ is a half of a wavelength at the desired frequency. Furthermore, the electrical length of the slot line between the stubs $\left(\mathrm{d}_{\mathrm{s}}\right)$ must also be half of a wavelength to prevent cancellation. With this excitation method, the E-field distribution on the antenna is shown in Fig. 4a. This shows the potential difference between the parasitic core and the ground plane to be zero at the centre of the slot because of the structure symmetry and opposing excitation.

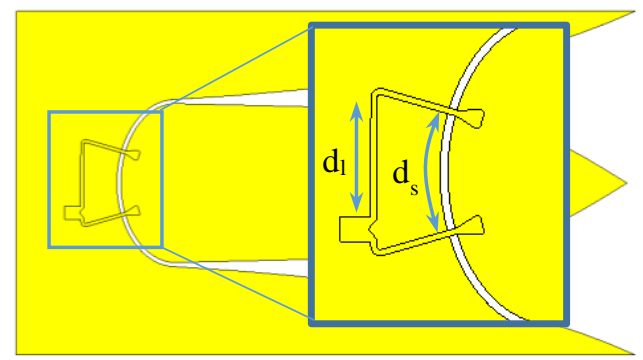

Fig. 2: Excitation method 1; parasitic core element

Fig 3 shows the excitation method 2 with a small change from exciting method 1 . There is a small conducting strip placed between the core and ground plane at the slot centre, hence the core is no longer parasitic.

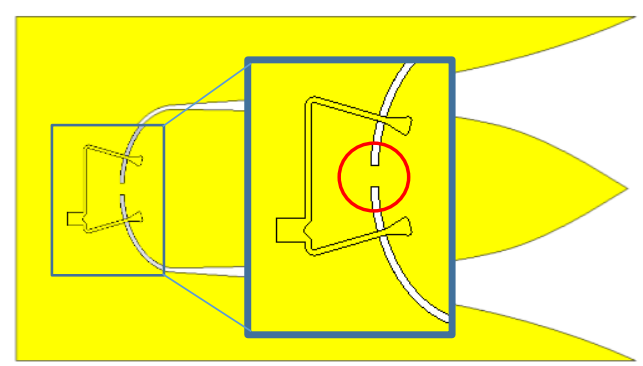

Fig. 3: Excitation method 2; connected core element

Fig. $4 \mathrm{~b}$ shows the E-field on the antenna with the conducting strip placed across the core and ground plane. The figures show that the modes are the same as excitation method 1 (parasitic core). Thus, the connecting strip does not effect to the slot mode.

The previously unreported connection strip to the core enables improved feed arrangements. A feed can be brought into the core and allows excitation from inside the core without affecting the mode and is the basis of further excitation methods. Fig. 5a and b show two of these feed arrangements. Method 3 is an inverse of method 2 in which a transmission line from outside crosses to the core at the strip connection and feeds the two stubs. These stubs excite the slot from the inside. This method also requires a half wavelength difference in electrical length of the two feed lines.

Excitation method 4 shown in Fig. 5b employs two stubs crossing the slot from opposite directions. One is from outside and the other one is from the inside. The two transmission lines from the T-divider to the stubs have the same length.
A major benefit of this method, enabled by the strip connection to the core, is that there is no need to provide an $180^{\circ}$ phase difference in the lines because two stubs have opposite directions. Therefore, the feed frequency dependence is removed and the two Vivaldi slots can maintain uniform phase over a wide range of frequencies.

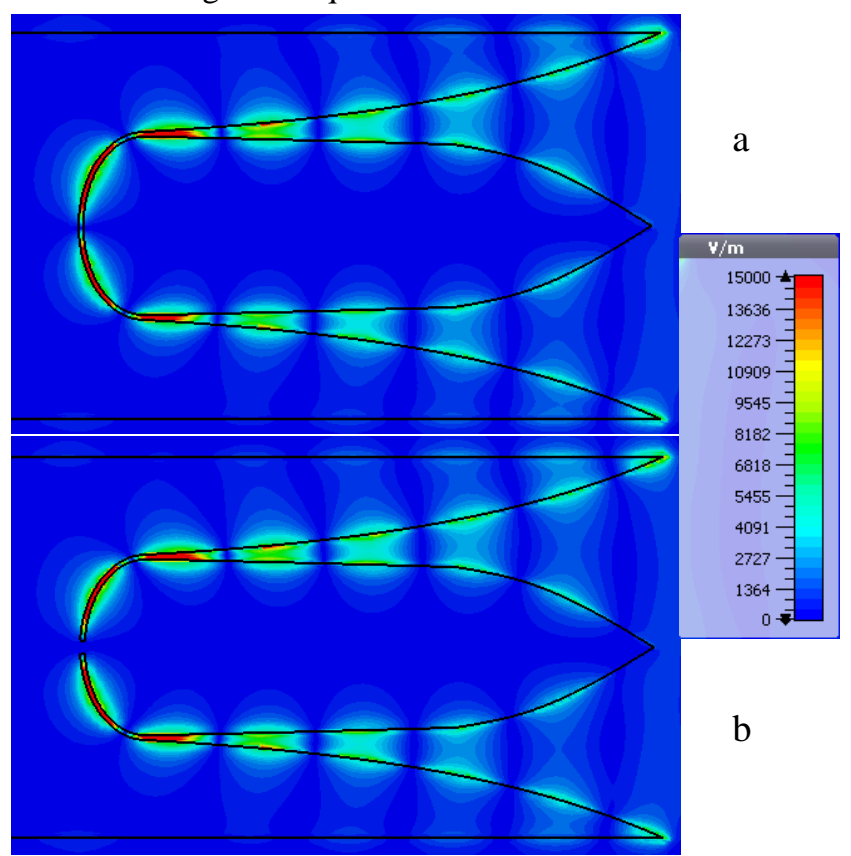

Fig. 4: E-field on the antenna without (a) and with (b) conducting strip placed across the core and ground plane.
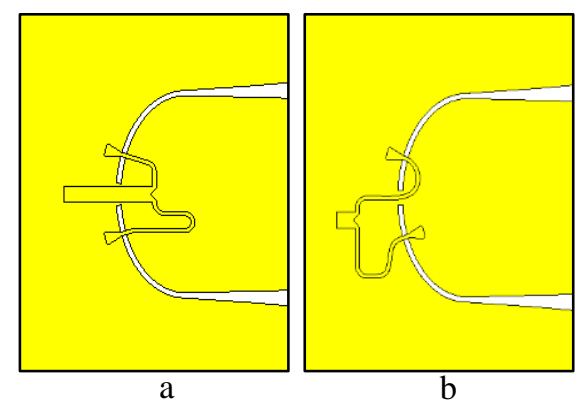

Fig. 5: Excitation method 3 (a) and 4 (b)

An investigation of the balance of the E-fields for two Vivaldi slots in the antenna was carried out by simulation of maximum IEEE-gain and far-field E-plane beam-squint for the antennas using excitation methods 2 and 4.

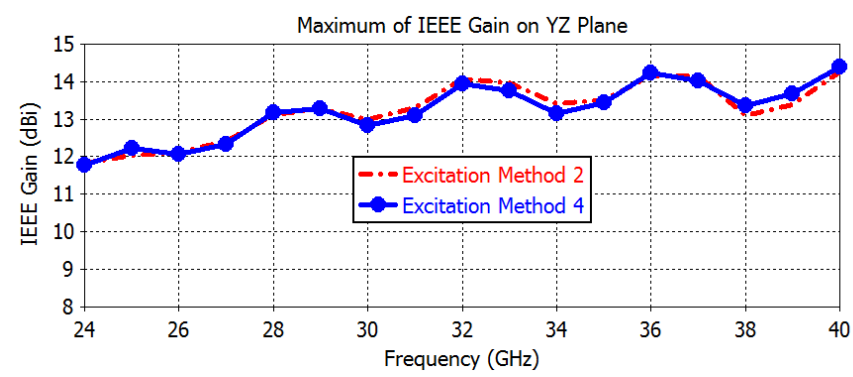

Fig. 6: Maximum IEEE-gain vs. frequency for antennas using excitation methods 2 and 4. 
Fig. 6 shows the maximum IEEE-gain of the antennas, which are nearly the same over the full frequency band for the two excitation methods, although there is significant E-field imbalance at the lower and upper frequencies for excitation method 2. Excitation method 4 has a good E-field balance across the full frequency band, which is shown in the superior beam-squint performance in Fig. 7 .

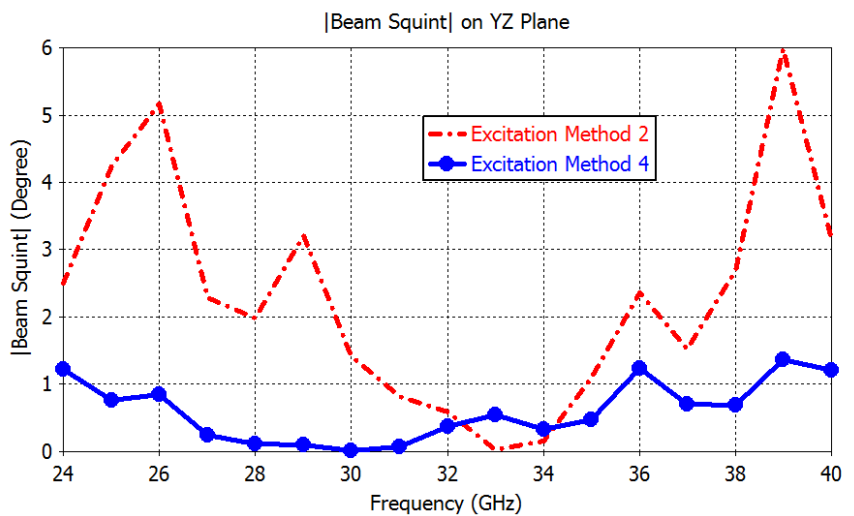

Fig. 7: E-plane beam-squint for excitation methods 2 and 4

\subsection{Improvement of gain}

Excitation method 4 is used in the next step of the design. To increase gain, the antenna size is increased in length $L v$ and width $W v$. Specifically, $L v$ is increased to $71.0 \mathrm{~mm}$ and $W v$ is increase to $31.0 \mathrm{~mm}$. Fig. 8 shows the antenna structure and the excitation method.

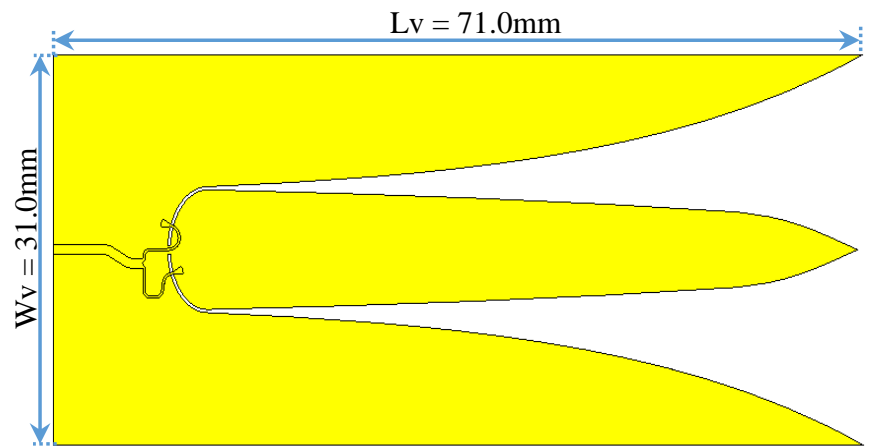

Fig. 8: Antenna structure and novel feed arrangement

The strip connection to the core element is an important part of the antenna, so, an examination how the length of the core element affects the gain is made. Fig. 9 illustrates the change in the length of the core element - Le from $30.25 \mathrm{~mm}$ to $80.25 \mathrm{~mm}$ with 6 steps.

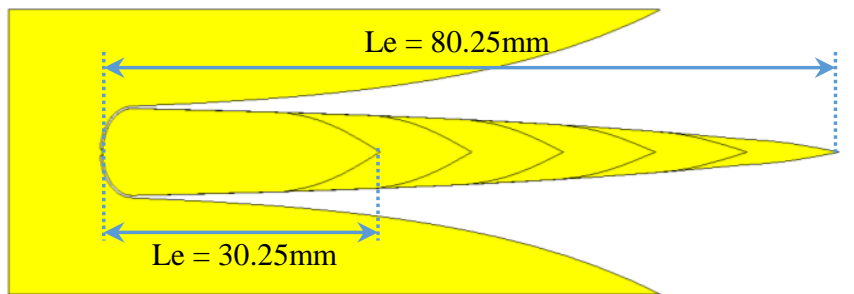

Fig. 9: Change in the length of the core element

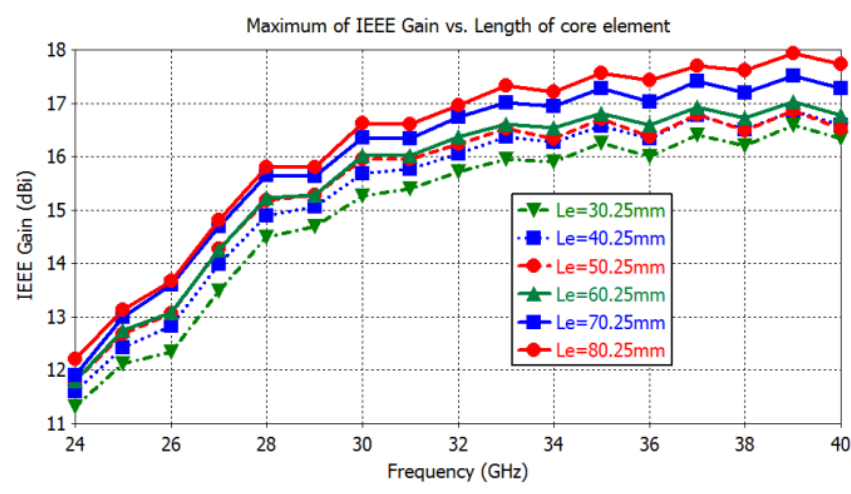

Fig. 10: Effect of the length of the core element on gain

Fig. 10 shows the gain trend as the length of the core element (Le) increases. However, in practice, there is a need to tradeoff gain increase against excessive antenna size. The length of the core element is chosen at $80.25 \mathrm{~mm}$ and the total length of the antenna is $91 \mathrm{~mm}$. The modelled antenna with an SMKconnector is shown in Fig. 11.

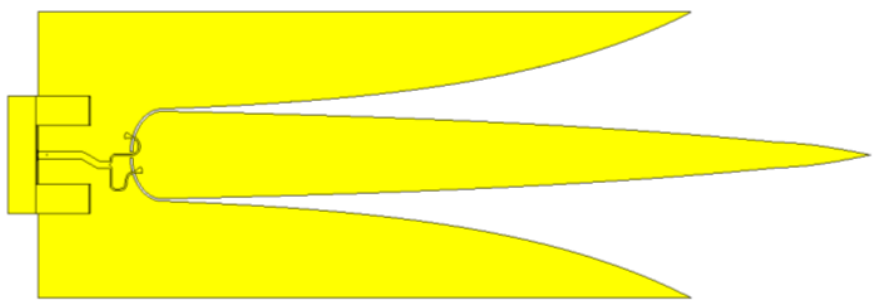

Fig. 11: Proposed structure

\section{Results and Discussion}

Fig. 12 shows the prototype of the antenna. Fig. 13 shows simulation and measurement results of S-parameters of the antenna.

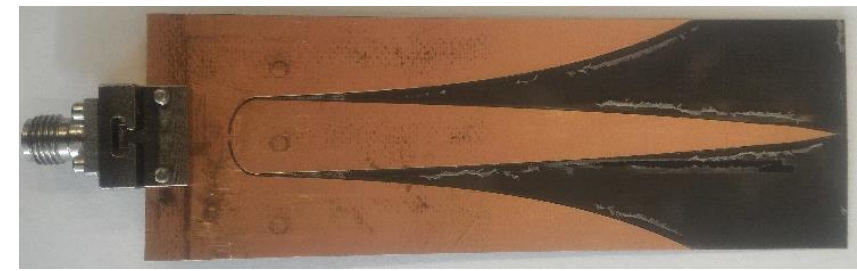

Fig. 12: Photo of the prototype

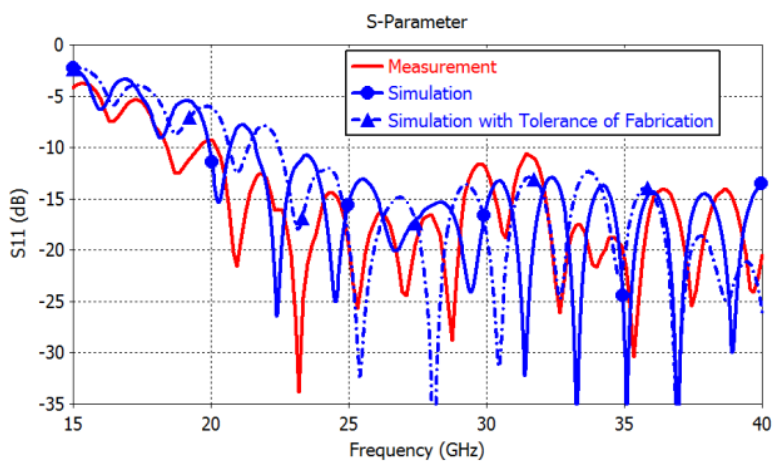

Fig. 13: S11 of the antenna 
The results reveal that the matching characteristic of the antennas is good over the full Ka-band (24-40 GHz). The maximum gain is shown in Fig. 14. The measurement result shows that the maximum gain reaches $16.9 \mathrm{dBi}$ and is better than $14 \mathrm{dBi}$ over the full Ka-band.

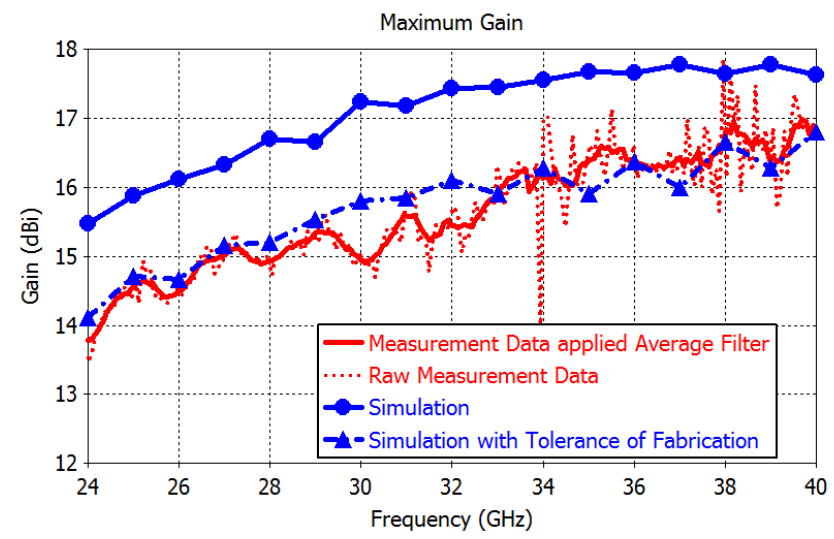

Fig. 14: Maximum gain versus frequency

Table 2 shows that the maximum gain of the proposed antenna is greater than previously reported work.

\begin{tabular}{|c|c|c|c|}
\hline Antennas & $\begin{array}{c}\text { Frequency } \\
(\mathbf{G H z})\end{array}$ & $\begin{array}{c}\text { Max. Gain } \\
(\mathbf{d B i})\end{array}$ & $\begin{array}{c}\text { Dimensions } \\
\mathbf{( m m}^{3} \mathbf{)}\end{array}$ \\
\hline$[4]$ & $4.7-20$ & 14.8 & $166 \times 70 \times 0.76$ \\
\hline$[3]$ & $2.5-15$ & 14.5 & $150 \times 80 \times 1$ \\
\hline$[1]$ & Ka-band & 13.2 & $59 \times 8 \times 0.5$ \\
\hline Proposed & Ka-band & 16.9 & $91 \times 31 \times 0.25$ \\
\hline
\end{tabular}

Table 2: Comparison of maximum gain to previous reports

Radiation patterns of the antenna are shown at 24, 32 and $40 \mathrm{GHz}$ for the E-Plane and H-Plane in Fig. 15.

\section{Conclusion}

In this paper, a structure that combines a double slot Vivaldi antenna with a novel core element has been proposed to increase the range of maximum gain for Vivaldi antennas. A preferred planar technology excitation was selected for a wider bandwidth and balanced field radiation across two slots which contributed significantly to the overall gain and bandwidth performances. The maximum gain is $16.9 \mathrm{dBi}$, with better than $14 \mathrm{dBi}$ across the whole Ka-band.

\section{Acknowledgements}

This publication has emanated from research conducted with the financial support of Science Foundation Ireland (SFI) and is co-funded under the European Regional Development Fund under Grant Number 13/RC/2077.

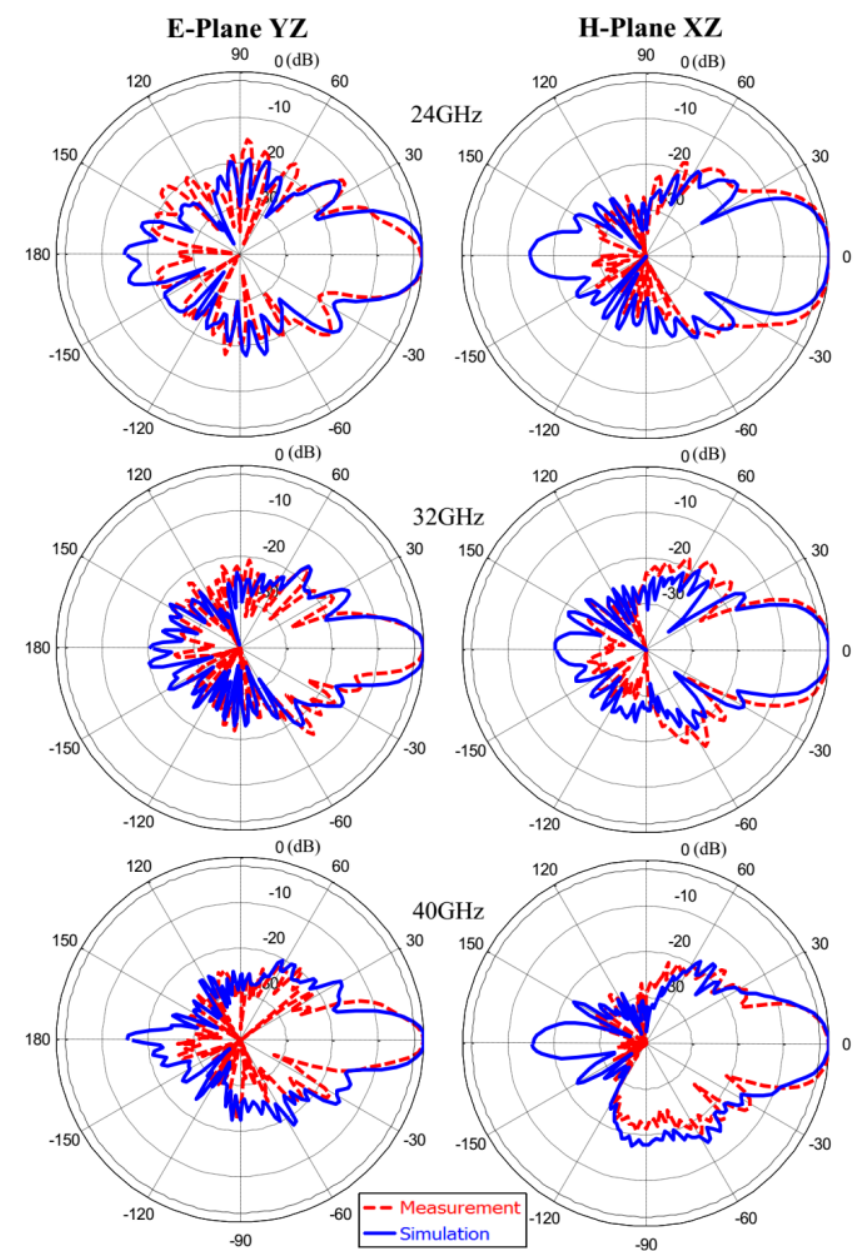

Fig. 15: Pattern on E-Plane (YZ) and H-Plane (XZ)

\section{References}

[1] J. Puskely, J. Lacik, Z. Raida, and H. Arthaber, "HighGain Dielectric-Loaded Vivaldi Antenna for Ka-Band Applications," IEEE Antennas Wireless Propag. Lett., vol. 15 , pp. 20042007, 2016.

[2] B. Zhou and T. J. Cui, "Directivity Enhancement to Vivaldi Antennas Using Compactly Anisotropic ZeroIndex Metamaterials," IEEE Antennas Wireless Propag. Lett., vol. 10, pp. 326-329, 2011.

[3] Y.-W. Wang, G.-M. Wang, and B.-F. Zong, "Directivity Improvement of Vivaldi Antenna using Double-Slot Structure," IEEE Antennas Wireless Propag. Lett., vol. 12, pp. 1380-1383, 2013.

[4] Y. Zhang, E. Li, C. Wang, and G. Guo, "Radiation Enhanced Vivaldi Antenna with Double-Antipodal Structure," IEEE Antennas Wireless Propag. Lett., vol. 16, pp. 561-564, 2017.

[5] I. T. Nassar and T. M. Weller, "A Novel Method for Improving Antipodal Vivaldi Antenna Performance," IEEE Trans. on Antennas and Propag., vol. 63, no. 7, pp. 3321-3324, 2015.

[6] K. Yang, A. Loutridis, X. Bao, P. McEvoy, and M. J. Ammann, "A coplanar Vivaldi Antenna with Integrated Filter for Ka-band," in Antennas \& Propag. Conf. (LAPC), 2016 Loughborough, pp. 1-4, 2016. 